\title{
Prediction of Offending: SARPO_-The Czech Tool for Assessment of Offenders' Criminogenic Risk and Needs
}

\author{
Vaclav Jiricka, ${ }^{1}$ Zuzana Podana, ${ }^{2}$ Michal Petras, ${ }^{1}$ and Jindrich Hurka ${ }^{3}$ \\ ${ }^{1}$ Department of Rehabilitation and Treatment, Prison Service of the Czech Republic, P.O. Box 3, 140 67, \\ Prague 4, Czech Republic \\ ${ }^{2}$ Department of Sociology, Charles University in Prague, Celetna 20, 11642 Praha 1, Czech Republic \\ ${ }^{3}$ Prison Plzen, Klatovska 202, 30635 Plzen, Czech Republic
}

Correspondence should be addressed to Vaclav Jiricka; vaclav.jiricka@volny.cz

Received 29 June 2013; Revised 19 November 2013; Accepted 19 February 2014; Published 24 March 2014

Academic Editor: Alexander Hirschfield

Copyright ( 2014 Vaclav Jiricka et al. This is an open access article distributed under the Creative Commons Attribution License, which permits unrestricted use, distribution, and reproduction in any medium, provided the original work is properly cited.

In the past three decades, developed prison and probation services have paid large attention to risk assessment tools predicting the probability of reoffending. This not only resulted in a more accurate classification of offenders, but also in a more informed choice of effective intervention helping to reduce relapse in offending behaviour. In terms of reducing the risk of reoffending intervention programmes considering the principle of criminogenic risks, needs, and responsivity proved successful, while imprisonment on its own, where intervention methods were not applied, showed only limited effectiveness. For historical reasons, the Czech Prison Service underwent a different development, although its objectives were similar. It was not until the beginning of a new millennium when the Czech prison system together with a newly created probation service decided to seek new methods of assessing offenders based on criminogenic risks. This paper presents development and results of the first Czech tool used for assessment of offenders' risks and needs, called SARPO (from the Czech abbreviation of Complex Analysis of Offenders' Risk and Needs).

\section{Introduction}

Offenders are imposed imprisonment sentences in order to prevent them from further offending, to rehabilitate them, and to protect the public. It means to protect the public not only in the time when the offender serves the prison sentence, but also after the offender is released. Developed prison and probation systems have lately turned their attention more and more to the latter aspect. They are aware of their share of responsibility for potential reoffending of the released offenders and they aim at mitigating the risk of reoffending, while assisting the released offender in reintegration into the community. For this purpose they have designed a large number of intervention methods.

In order to work with offenders it is necessary to have enough information about their attitudes towards themselves and others, what threats they pose to people that work with them and what chances of their rehabilitation there are. For this reason any intervention with the offender must be necessarily preceded by assessment mapping his/her personal features considering the situations in which the outputs will be used. These outputs may be different during imprisonment and after early release. Thus for a prison guard it will be important to know to what degree the offender is dangerous and whether he/she will present any risk of harm during the imprisonment both towards other people and to himself/herself. A therapist needs to assess any progress the offender has made in his/her own perception and any changes he/she has made in his/her attitudes. An early release board and the judge will be interested in knowing the likelihood of his/her reoffending after the release and of his/her lawabiding integration into the community. A probation officer will plan and organize the scheme of suitable intervention and make sure that the rehabilitation and reintegration of the released person is successful.

\section{Background}

2.1. Approaches to Offender Assessment. In the second half of the 20th century there was probably hardly a justice or 
prison system in the developed countries that would not be engaged in assessment and classification of offenders. A concise account of the development of assessment tools is given by Bonta [1] who distinguishes four generations of tools.

According to Bonta, the first generation of assessment tools was clinical judgments, which were unstructured and based on experience of the assessor. Bonta believes this assessment to be inaccurate and unreliable leaving little space for consideration of other circumstances of offending. For this reason, in the 1980 s, there came a second generation of tools using actuarial methods which started to emphasize so-called static factors, that is, those that could not be changed anymore: age, sex, start of the offending career, number of convictions, and other features typical of offending behaviour. This model showed higher predictive validity; nevertheless, it failed to match the criminogenic factors with intervention leading to rehabilitation of offenders. The 1990s brought about tools combining static and dynamic factors which built upon the premise that in order to be able to determine the risk of reoffending and to be able to choose a suitable intervention it is necessary to know both offender's risks and criminogenic needs. While some of the tools of the third generation sum the items to arrive at numeric risk scores, other approaches incorporate evidence-based information about risk factors and expert interpretation of the seriousness, frequency, or duration of these risk factors - such as structured professional judgments (SPJ). Although the SPJ do not present higher predictive validity than actuarial tools, they help to concentrate on influencing the offender. Since the introduction of the SPJ it has not been sufficient to ask just whether and to what extent the offender is dangerous and also why it is so and what can be done in order to change that. Not later than at the turn of the millennium there appeared tools that take into account the length and intensity of the proposed intervention according to the seriousness of risks and needs: intervention and offenders must correspond; they must be responsive. This enables designing the intervention to individual offenders and at the same time to predict their future behaviour if certain conditions are met. Therefore, case management is considered by some authors an integral part of the fourth generation tools [2].

At present, all the four generations of tools are in use at once. Common praxis in the Anglo-Saxon countries shows that different approaches may well coexist with each other: the clinical rating scale Psychopathy Checklist-Revised (PCLR) [3], the structured professional judgement HCR-20 [4], or the actuarial tools Violence Risk Appraisal Guide (VRAG) [5] or Level of Service Inventory-Revised (LMI-R) [6]. Nevertheless, also the interest of countries from continental Europe (especially German speaking countries) has been shifting from the clinical methods to validated predictive instruments targeted at certain groups, especially at violent or sexual offenders [7]. In terms of prediction of violent reoffending of offenders with a mental disorder and behaviour disorder, the effect size of the actuarial risk assessment $(r=0.30)$ is approximately three times higher than of clinical instruments (0.09); in predicting reoffending of sexual offenders, it is even more than four times higher (0.46 versus 0.10 ) [8]. This has been ascertained repeatedly in several studies. It begs the question whether omitting use of actuarial tools for prediction of risks should not be considered unethical and unprofessional [9].

2.2. Offender Assessment in the Czech Republic. In the former Czechoslovakia, prediction of offending behaviour and reoffending started to be dealt with from the end of the 1960s. It was the Correctional Education Unit of The Penitentiary Research Institute that substantially contributed to this activity and that, based on the outputs of the assessment, researched also options for applying intervention methods as part of "treatment of prisoners" [10, 11]. From the 1970s to the end of the 1980s there were a number of instruments designed for prediction of likelihood of offending career, structured as statistical tests [12]. Paradoxically enough, most of these intentions go back before the 1989 political revolution. The consolidation of the Czech prison system after the revolution took an entire decade when fundamental issues such as the approach to criminal law and prison system had to be addressed. Only with an increased emphasis on postprison intervention, creation of probation assistant positions at district and regional courts in 1996, with establishment of the Probation and Mediation Service of the Czech Republic in 2001 and upon learning about other countries' experience, the stress started to be placed on targeted and effective intervention, which must be necessarily preceded by appropriate assessment speaking the same language.

One of the first Czech prediction tools was Veverka's Green Test which evaluated information relevant from a psychiatric point of view and his Blue Test focusing on data about offender's criminal history and social background and identifying "risk" factors that make the offending career more likely $[13,14]$. A large longitudinal research of reoffenders served as a basis of Dufek's individual prediction of offending, distinguishing 36 weighed prediction factors in socio-legal, psychological, and psychiatric context [15]. A set of 14 "static" predictors influencing reintegration of offenders released from prison was drawn up by Neumann and Vonkova in their social prediction instrument of offending, called RAOK [16]. Heretik's Prognosis Index of Reoffending, called PIR [17], rendered a percentage likelihood of specific and general reoffending; however, it did not distinguish between static and dynamic factors and employed also projective methods.

A different approach when preparing his predictive critical sets of features was taken by Dobrotka [18] who distinguished between social, personal, and symptomatic (today we would call them criminogenic) factors. Using a percentage representation of critical factors, he was probably the first Czech researcher who introduced scaling of predictive outputs while creating a scale ranging from positive to very bad prognosis.

For the time being, the last product in the Czech context is a working version of a five-item prediction instrument based on analysis of static data on the offending history of 100 persons drawn up by the Institute of Criminology and Social Prevention [19]. This tool, which uses only static factors, is 
designed for the needs of workers in the justice or for judicial experts in the field of psychology, and it has not yet been validated.

Compared to the development of predictive and assessment tools in the world, there were certain differences in the Czech environment.

(a) Although the tools intended to implement clinically relevant elements, in general they hardly ever regarded the possibility that an offender could change. Therefore, they concentrated mostly on static factors only.

(b) Some tools provided comprehensive prediction of reoffending, but had hardly any impact on prisoners' treatment and rehabilitation. If taken in account, interventions were not aiming at mitigation of the risk of reoffending.

(c) The tools did not work with criminogenic factors in the sense of criminogenic risk and needs.

(d) If we were to classify the Czech tools within the above generations of tools used in the world, they would belong, with the exception of Dobrotka's instrument, to the second generation of actuarial tools, even in cases where they included dynamic factors; the outputs of their dynamic part were not taken into account more than just by including them in numeric risk scores.

(e) And the most important one is that the tools never left the academic ground and were never employed in the judicial, correctional, and postpenitentiary routine.

At present, the Czech prison and justice systems use almost invariably psychodiagnosis and questionnaire methods, which either do not belong to assessment tools in terms of risk and needs assessment or which belong to the clinical generation. The emphasis is placed on individual approach; the collection of data from the prisoners is very large, while paying attention to the personality of the offender and obviously following the structure and function of judicial expert opinions. On the one hand, these are strengths that are traditionally and permanently inherent of the Czech environment. On the other hand, what may be seen as a weakness is that this information has not been used appropriately and its potential has been left unexplored. Thus, the acquired information has served the purpose of protection of the public in terms of reducing reoffending only to a limited degree. Therefore there is a need to have a completely new tool that would take into account the abovementioned risk and needs principles.

2.3. Risk and Needs Assessment. The assessment of offenders, as it has been perceived generally by the modern prison [20] or probation systems [21] in the recent decades and as it is perceived also in this paper, is based on offender's criminogenic risk and needs. Most often the assessment is done in connection with statement of the judgment, classification of the prisoners, assessment of the prisoner during his/her imprisonment, and consideration of early release and as part of parole.

The objective of risk assessment is primarily to predict likelihood of offender's reoffending and to adjust further intervention to the offender based on this prediction. Risk assessment is a process in which the offender is assessed based on selected variables which, as the evidence proved, increase the likelihood of failure.

These variables, called risk factors, are further subdivided into static and dynamic factors. Both these categories are causally linked to the offending behaviour, where the static factors are based on the history and they are fixed, while the dynamic factors are currently present and they can be influenced. The examples of static factors include the age at which the offender committed his/her first offence, history of the previous sentences, sex, type of offence, or motivation for committing previous offences. Typical dynamic factors include financial situation, employment, attitudes encouraging criminal conduct, addictions, family relations, criminal friends and acquaintances, or leisure time activities. In addition, there are other factors that come into play which proved to be associated with committing crime (e.g., low selfconfidence, depression, anxiety, and fear), yet they are not causally linked [1].

Research into criminal conduct [22-24] and especially recent studies evaluating the effectiveness of intervention programs [25-27] showed that the principle of risk and needs as such is not enough to achieve good results or to be precise that the same factors may have a different impact on different respondents (the youth, adults). Such examples led to respect personal qualities of individuals, who respond to the above factors in a diverse way. In connection with this, Andrews and Bonta [6] introduced a so-called responsivity principle which states that the intensity and length of the intervention should reflect the degree and quality of criminogenic risk and needs.

Assessing criminogenic risk and needs helps-unlike other assessment methods-to define and address the management of prisoners as a whole: it helps to define who the target of the intervention is (in case of prisoners with highrisk of harm or risk of reoffending), what the intervention objectives are (mitigation of the risk of reoffending, that is, criminogenic needs, rather than, for example, clinical symptoms), what intervention strategy in terms of duration and intensity to take, while having in regard the motivation factors, the degree to which the offender is likely to be influenced and how he/she learns based on the responsivity principle (taking into account the current possibilities and abilities of the assessed person), and how the effectiveness of the intervention is measured.

\subsection{Development of Assessment Tool SARPO. The SARPO} Project (from the Czech abbreviation Complex Analysis of Offenders' Risk and Needs) is a joint project of the Czech Prison Service and the Czech Probation and Mediation Service which commenced as a part of the PHARE Project in 2003 by setting up a multidisciplinary team. At the beginning the team included employees of the Prison Service, Probation and Mediation Service, National Probation Service 


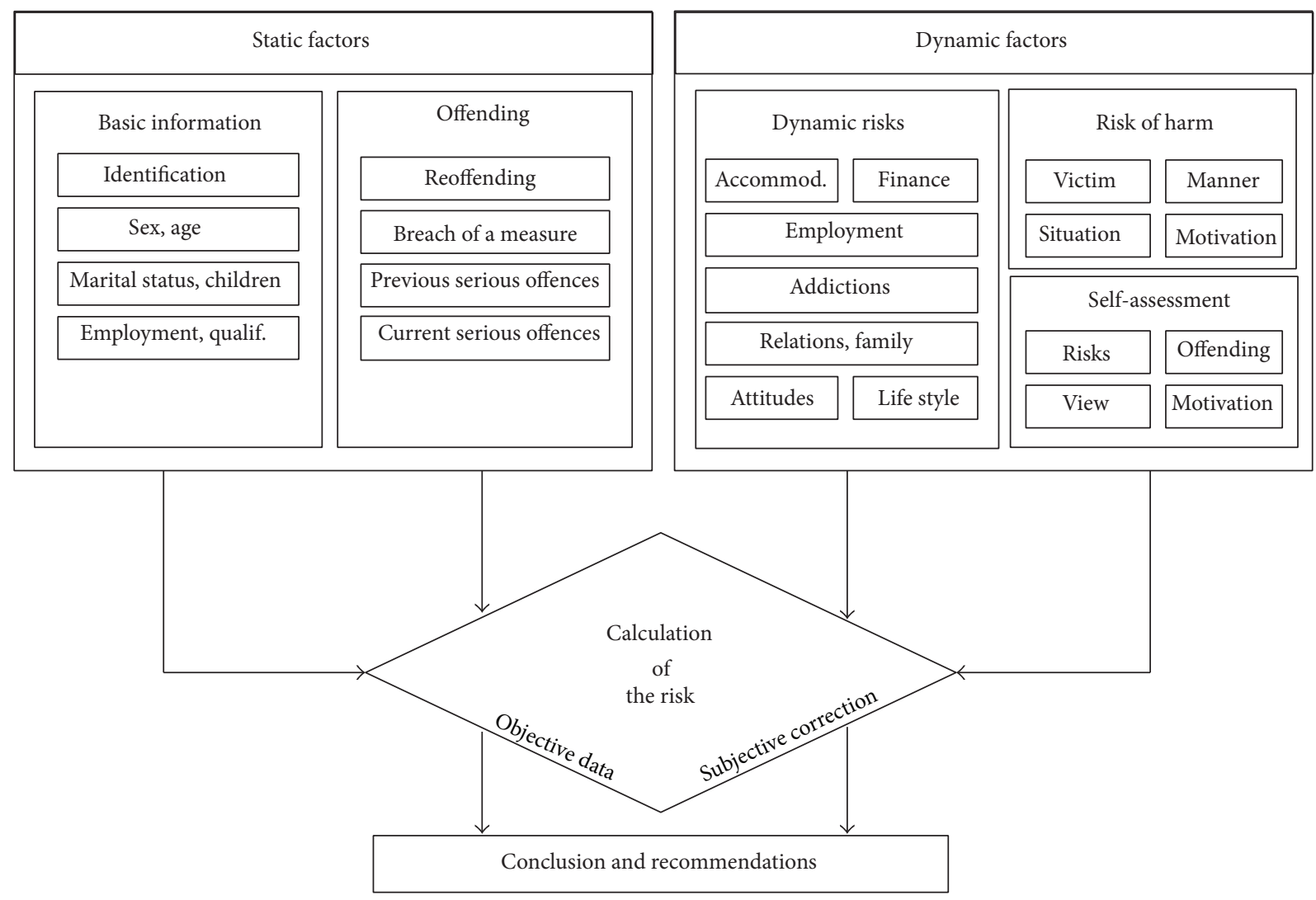

FIGURE 1: Basic parts of the SARPO 1 instrument and assessment mechanism.

of England and Wales, the Czech Institute of Criminology and Social Prevention, City Centre of Social Services and Prevention, Association for Probation and Mediation in Justice, Municipal Court in Brno, State Prosecution Office in Prague 4, and the Police President Office of the Czech Republic. Once the PHARE Project ended in 2004, a team of prison and probation experts was established and strove to create its own assessment instrument which could be used by both Prison Service and Probation and Mediation Service.

Originally the SARPO Project was based on the Offender Management System assessment tool (OASys) which is currently used by the prison and probation service in England and Wales [28] and is considered a high quality European tool for prediction of offending [29]. However, the new assessment tool was intended to be adjusted to Czech conditions, taking into account specific sociocultural aspects and the legal environment, so that its conceptual structure could reflect the practical needs of assessors as much as possible. It was therefore decided to develop an own independent tool. The first version of the tool SARPO 1 was finished and presented to the professional public in 2006 [30, 31]. Figure 1 shows the basic parts of the SARPO 1 instrument and assessment mechanism.

2.5. Philosophy and Structure of SARPO. SARPO uses static and dynamic risk factors to determine risk and needs. The risk in this context refers to two concepts: the risk of harm and the risk of reoffending [32]. The risk of harm is defined as a serious harm jeopardizing life or causing trauma and it is difficult or impossible to be overcome from both the physical and mental viewpoint. This risk determines the degree of serious harm caused by any possible future offending especially of violent and sexual offenders, while regarding the potential victims.

The risk of reoffending reflects the likelihood of a future event of loss, damage, or harm. Here the risk of reoffending is mainly determined based on the offending history, and the likelihood of his/her further offending career is assessed by making a profile of the offender.

The risk itself includes needs of the offender. The need in this sense is perceived as a criminogenic dynamic factor which can, in most cases, be targeted. For instance, a person can find a new job, change his/her accommodation, change his/her attitudes, or stop using drugs, which, as a consequence, results in reducing his/her need to commit crime for the above reasons.

An important part of the tool is evaluation of offender's motivation - to what extent he/she is capable and willing to participate in making the changes in his/her life. All the outputs of the risk and needs assessment are afterwards translated into a final plan of subsequent intervention.

The basic structure of the tool consists of five parts. The first one evaluates information about the offender's criminal history focusing on specific features of the offending. The second part of the tool analyses data relating to the 
circumstances, factors, and incentives relevant in the overall context of the offender's criminal conduct, with a view to a potential object of harm. The third part is made of a set of dynamic risk factors (a total of 40) divided into six areas: housing, employment, finance situation, addictions, family and social relations, and attitudes and life-style. The fourth part contains a self-assessment form whose aim is to obtain feedback from the offender who himself/herself fills in this part. The last part is the final output where the results of the analysis of the offender's risk and needs are interpreted, the offender's motivation to address the difficult issues is assessed, and recommendation is made by the assessor, including proposed further treatment of the assessed person.

SARPO makes use of both objective and subjective methods of assessment. The objective method is represented by calculation of objectively determined risks on a scale from 0 to 10 points for each dynamic factor. Based on his/her justifiable expertise, the assessor is allowed to make a correction up to 2 points up or down. In addition to this, the calculated risks are compared with the self-assessment items made by the offender.

\section{Data}

The pilot study designed to test the predictive validity of the SARPO instrument started in 2007 and was conducted by trained (all participating assessors underwent a three-day intensive training on using the instrument) assessors in 16 prisons and 19 probation centres across the Czech Republic. The original aim was to obtain a sample of 500 assessments in total: 350 by the Prison Service and 150 by the Probation and Mediation Service. The pilot study targeted two groups of respondents: prisoners prior to filing an application for an early release (Prison Service) and persons just after being released on parole. A total of 513 assessments were carried out: 379 prisoners and 134 persons on probation.

Evaluation of the pilot data was conducted in three modules over the next five years. In the first phase, basic information including quantitative, qualitative, and methodological evaluation was carried out and formulas for static and dynamic risk assessment were calculated. In the second phase, a certain correction of these formulas was suggested.

Finally, data on reincarceration of offenders from the Prison Service sample only were collected during spring 2012. Only those prisoners were involved who were actually granted conditional release from prison after the SARPO assessment and where the time period from their release lasted for no less than 3 years. Out of 379 tracked prisoners, only 282 were usable for the purpose of analysis of reoffending. The other prisoners were still in prison in 2012, or the time from their release was still shorter than 3 years. The analyzed dataset consists only of male offenders since the number of women included into SARPO study was minimal.

\section{Measures}

The indicator of recidivism used in this study is a new incarceration within 3 years after the release from prison. The recidivism rate is examined with relation to a set of static and dynamic risk factors. Static risk factors include age at the time of release, age of the first conviction, total number of convictions, crime intensity measured by Copas rate [33], and seriousness of offending which is a proportion of prison sentences out of all convictions. (The indicator of seriousness was dichotomized before it was used in analysis. Values lower than two-thirds were coded 0 (less serious category) and larger values were coded 1 (highly serious category).)

Dynamic risk factors-36 items with dichotomous scales coded 0 if the risk is not present and 1 if presentwere divided into six groups which covered the following areas: accommodation, employment, finance, addictions, family/peers, and personality/attitudes. A separate risk scale for each group was constructed as a mean of respective items and the scales were subsequently linearly transformed to range from 0 to 10 .

In addition, overall scales of static and dynamic risks were constructed. The dynamic risk scale was designed simply as a mean of six subscales (Cronbach's alpha $=0.86$ ) and the scale was linearly transformed to allow values from 0 to 100 . Similar approach is, however, not possible in case of static risk scale since the indicators have different units and therefore logistic regression was employed for the development of the overall scale (number of convictions was not included in the logistic model due to multicolinearity as it is directly related to Copas rate index). The scores were subsequently multiplied by 100 so that the scale ranges from 0 to 100 . Finally, these two scales were combined into the "overall risk scale" (computed as a mean of both scales). Generally, the higher the score of any risk scale, the higher the risk of the person in the respective area. For descriptive statistics of all scales, see Table 1.

Construction of all scales except for the static risk scale was developed independently from the reincarceration measure and therefore the strength of relationships to the dependent variable is not biased. We have adopted this approach because our sample size is limited and split-half cross validation is not possible. On the other hand, static risk scale was developed by fitting a logistic regression model with reincarceration as a dependent variable and therefore the strength of the relationship between the scale and reincarceration is likely to be overestimated and should be evaluated by further research.

\section{Results}

Table 2 shows the basic overview of the sample. The reincarceration rate within the 3 years following the release from prison reaches $37 \%$. The sociodemographic profile of the sample reflects the characteristics of prison population in the Czech Republic-most offenders are young, single, or divorced and their level of education is low. The sample includes both offenders who were granted conditional release-either with supervision (17\%) or without it $(37 \%)$ and offenders who served the whole sentence (47\%).

The associations between reincarceration and risk factors and scales are presented in Table 3. Out of static risk factors, the relationship to recidivism is the strongest for the age of 
TABLE 1: Risk scales-descriptive statistics.

\begin{tabular}{lcccc}
\hline & Mean & S.D. & Min/Max & \\
\hline Dynamic risks/needs subscales & & & $0 / 10$ & $0 / 6.7$ \\
$\quad$ Accommodation & 2.9 & 3.4 & $0 / 10$ & $1.7 / 6.7$ \\
Employment & 4.5 & 3.4 & $0 / 10$ & $4.0 / 10.0$ \\
Finance & 6.2 & 3.0 & $0 / 10$ & $0 / 8.3$ \\
Addictions & 4.4 & 3.8 & $0 / 10$ & $2.0 / 7.0$ \\
Family, peers & 4.7 & 3.0 & $0 / 10$ & $2.0 / 6.0$ \\
Personality and attitudes & 4.3 & 2.6 & $2.6 / 83.2$ & $32.6 / 59.0$ \\
Static risk scale & 46.3 & 18.5 & $0 / 97.9$ & $26.8 / 65.7$ \\
Dynamic risk scale & 46.4 & 24.3 & $2.0 / 84.4$ & $32.3 / 60.9$ \\
Overall risk scale & 46.4 & 18.4 & & \\
\hline
\end{tabular}

TABLE 2: Descriptive statistics.

\begin{tabular}{lcc}
\hline & $n$ & $\%$ \\
\hline Reincarceration & 105 & 37.2 \\
$\quad$ Yes & 177 & 62.8 \\
$\quad$ No & & \\
Type of release & 131 & 46.5 \\
$\quad$ Release & 48 & 17.0 \\
Conditional release with supervision & 103 & 36.5 \\
Conditional release & & \\
Age when released & 99 & 35.1 \\
19-29 & 109 & 38.7 \\
30-39 & 74 & 26.2 \\
40+ & & \\
Education & 20 & 7.1 \\
Less than primary & 109 & 38.7 \\
Primary school & 116 & 41.1 \\
Vocational school & 36 & 12.8 \\
High school or higher & 1 & 0.4 \\
No answer & & \\
Marital status & 28 & 9.9 \\
Married & 165 & 58.5 \\
Single & 89 & 31.6 \\
Divorced & 282 & 100.0 \\
\hline Total & &
\end{tabular}

the first conviction $(r=-0.26)$ and crime intensity $(r=0.26)$ and also the other risk factors are associated in the anticipated direction. All scales capturing dynamic risk factors are related to recidivism as well. The highest correlation exceeding 0.3 is found for employment, finance, and personality/attitudes scales. Consequently, both static and dynamic risk scales are substantially associated with recidivism with correlation coefficient $r=0.36$ and $r=0.35$ and, furthermore, their combination into an overall risk scale gains even a better result $(r=0.42)$. (Unlike dynamic risk scale, static risk scale was based on post hoc analysis and, therefore, the strength of association is likely to be overestimated.)

All three scales-static, dynamic, and overall-seem to be fairly good predictors of recidivism and can well distinguish

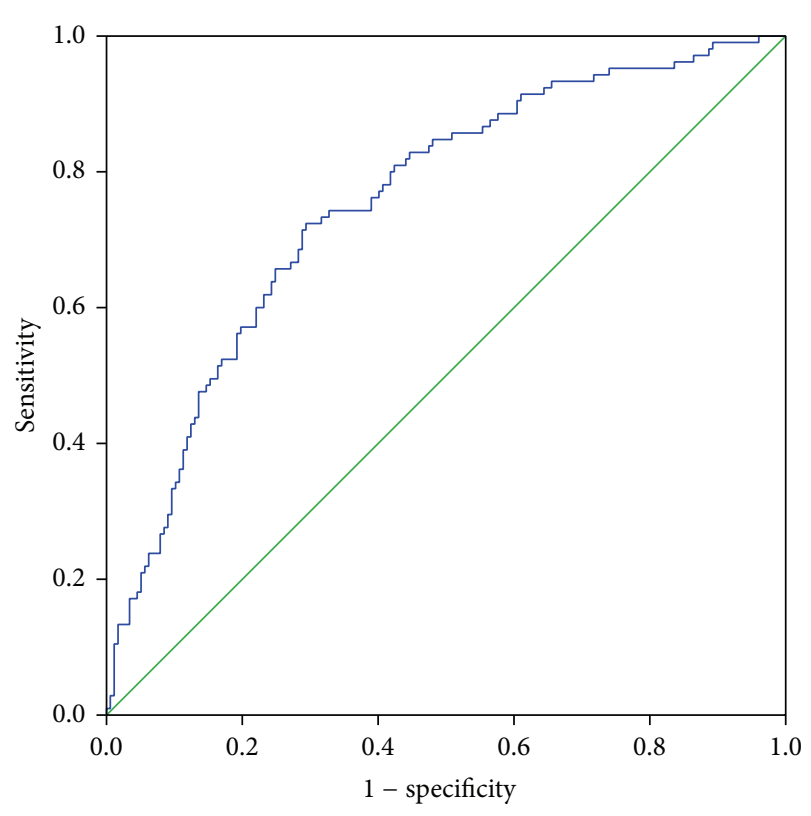

Figure 2: ROC analysis for the overall risk scale.

between low-risk and high-risk offenders as can be observed in Table 4. In addition, ROC curve analysis for the overall risk scale $(A U C=0.74)$ supports good usability of the scale as well (see Figure 2).

\section{Conclusion and Discussion}

The present results suggest that the instrument is well designed. It is not to expect that SARPO will accurately distinguish between those who fail from those who will commit no crime again. Therefore, we consider the current results as very good, especially as they come from a pilot study and are based on a limited sample size. The predictive ability of SARPO seems not to be much worse than analogous international tools (e.g., $[8,34]$ ).

The results of the pilot study also clearly demonstrate the relevance of static and dynamic factors to estimate the risk of failure. On the other hand, it should be noted that this is only a pilot study based on a limited sample. Further research will 
TABLE 3: Risk factors and their association with reincarceration.

\begin{tabular}{lccc}
\hline & $\mathrm{M}^{+}($S.E. $)$ & $\mathrm{M}^{-}$(S.E.) & \\
\hline Static risks & & & \\
First conviction (age) & $22.6(0.56)$ & $19.2(0.47)$ & -0.26 \\
Number of convictions & $4.6(0.25)$ & $6.2(0.34)$ & 0.23 \\
Crime intensity (Copas rate) & $-1.8(0.05)$ & $-1.5(0.05)$ & $0.38(0.05)$ \\
Seriousness of offending & $0.24(0.03)$ & $32.3(0.85)$ & \\
Age & $35.3(0.66)$ & & \\
Dynamic risks/needs & & $3.8(0.35)$ & -0.14 \\
Accommodation & $2.4(0.24)$ & $5.9(0.31)$ & \\
Employment & $3.7(0.25)$ & $7.5(0.26)$ & 0.19 \\
Finance & $5.5(0.22)$ & $5.6(0.37)$ & $0.3(0.30)$ \\
Addictions & $3.8(0.27)$ & $5.3(0.23)$ & 0.32 \\
Family, peers & $4.0(0.21)$ & $54.7(1.6)$ & 0.23 \\
Personality and attitudes & $3.7(0.19)$ & $56.2(2.6)$ & 0.28 \\
Static risk scale & $41.0(1.4)$ & $55.4(1.6)$ & 0.31 \\
Dynamic risk scale & $38.3(1.7)$ & 0.36 \\
Overall risk scale & $38.7(1.4)$ & 0.35 \\
\hline
\end{tabular}

Note. $\mathrm{M}^{+}$: means for the group "no reincarceration"; $\mathrm{M}^{-}$: means for the group "reincarceration."

TABLE 4: Proportion of reincarceration for quartiles of the risk scales.

\begin{tabular}{lccc}
\hline & $\begin{array}{c}\text { Static risk } \\
\text { Reincarceration (\%) }\end{array}$ & $\begin{array}{c}\text { Dynamic risk } \\
\text { Reincarceration (\%) }\end{array}$ & $\begin{array}{c}\text { Overall risk } \\
\text { Reincarceration (\%) }\end{array}$ \\
\hline 1st quartile of the scale & 18.5 & 17.1 & 11.4 \\
2nd quartile of the scale & 25.0 & 27.1 & 26.8 \\
3rd quartile of the scale & 49.2 & 43.7 & 44.3 \\
4th quartile of the scale & 63.1 & 60.0 & 66.2 \\
\hline
\end{tabular}

be needed to evaluate the current construction of the static risk scale and to develop appropriate weights for subscales to create a more effective dynamic risk scale. It can be expected that the predictive ability of a modified tool will be even higher and will improve.

At this point we should mention why the Prison Service of the Czech Republic has decided to develop and introduce a new tool instead of implementing already established and proven international tools. Building a better tool for prediction of reoffending should not be the sole aim of risk prediction research, as it is just one link in the risk assessment-prediction-management. Risk assessment should lead to providing better treatment and continuity of care. We assume that the risk, needs, and responsivity principles provide a useful theoretical framework for interventions reducing risks of reoffending. The basic characteristics of Czech offenders do not seem to differ from populations of prisoners in other countries very much which gives support to the assumption that the majority of risk factors are similar across the developed countries. On the other hand, the tool SARPO was developed to refer to and recommend treatment solutions. Therefore a fundamental knowledge of the culture, cultural habits including drug use, kind of crime associated with the behavior of certain subcultures and ethnics, and also the legislative and socioeconomic system and social services is inevitable. Appropriate risk assessment can identify high-risk individuals in need of tailor-made management and available intervention. Using tools with dynamic risk predictors to assess risk can identify appropriate changeable treatment targets. Assessment tools with dynamic or changeable predictors, such as the HCR-20, OASys, or the LSI-R, can accomplish some of these tasks provided but are little connected with the available care options in the country.

More research involving prospective followups of large samples is clearly needed in the future. Since the tool SARPO has already been implemented into the practice of the Czech Prison Service, the number of assessments is rapidly increasing (over 9500 cases by the end of January 2014) which will soon allow us to conduct more elaborate analyses. In particular, there is a need to improve the predictive validity and to be more specific on dynamic risk scales.

Future directions and developments may lead SARPO towards assessing the difference between the risks identified by imprisonment and later on, either before applying for parole or on a regular basis. This means to develop, validate, and implement additional set of items which will be able to capture and interpret the relevant changes. This would open up completely new possibilities for evaluating the effectiveness of various interventions for various target groups of prisoners or to monitor the progress in therapy.

For the present, the Prison Service of the Czech Republic has a modern assessment tool, which has a number of 
advantages over simple static instruments or solely clinical tools.

\section{Conflict of Interests}

The authors declare that there is no conflict of interests regarding the publication of this paper.

\section{References}

[1] J. Bonta, "Guidelines for selection and use," Criminal Justice and Behavior, vol. 29, no. 4, pp. 355-379, 2002.

[2] D. A. Andrews, J. Bonta, and J. S. Wormith, "The recent past and near future of risk and/or need assessment," Crime and Delinquency, vol. 52, no. 1, pp. 7-27, 2006.

[3] R. D. Hare, The Hare Psychopathy Checklist-Revised, MultiHealth Systems, Toronto, Canada, 1990.

[4] C. D. Webster, K. S. Douglas, D. Eaves, and S. D. Hart, HCR20: Assessing the Risk for Violence (Version 2), Mental Health, Law, and Policy Institute, Simon Fraser University, Vancouver, Canada, 1997.

[5] G. T. Harris, M. E. Rice, and V. L. Quinsey, "Violent recidivism of mentally disordered offenders: the development of a statistical prediction instrument," Criminal Justice and Behavior, vol. 20, pp. 315-335, 1997.

[6] D. A. Andrews and J. Bonta, The Level of Service InventoryRevised, Multi-Health Systems, Toronto, Canada, 1993.

[7] F. Urbaniok, J. Endrass, A. Rossegger, T. Noll, W. T. Gallo, and J. Angst, "The prediction of criminal recidivism: the implication of sampling in prognostic models," European Archives of Psychiatry and Clinical Neuroscience, vol. 257, no. 3, pp. 129-134, 2007.

[8] J. Bonta, M. Law, and K. Hanson, "The prediction of criminal and violent recidivism among mentally disordered offenders: a meta-analysis," Psychological Bulletin, vol. 123, no. 2, pp. 123142, 1997.

[9] V. L. Quinsey, G. T. Harris, M. E. Rice, and C. A. Cormier, Violent Offenders: Appraising and Managing Risk, American Psychological Association, Washington, DC, USA, 1998.

[10] J. Cepelak, "Moznosti aplikace principu terapeutickeho spolecenstvi v systemu napravne vychovy. Material ke studiu a diskusi," Vyzkumny ustav penologicky SNV CSR, 1980.

[11] M. Urbanova, "Prispevek k psychologicke analyze efektu penitenciarni resocializace," Bulletin Vyzkumneho Ustavu Penologickeho SNV CSR, vol. 3, 1977.

[12] S. Blatnikova and K. Netik, Predikce Vyvoje Pachatele, IKSP, Praha, Czech Republic, 2008.

[13] M. Veverka, "Kriteria Glueckovych v nasem kriminologickem vyzkumu," Sociologicky Casopis, vol. 1, pp. 38-34, 1969.

[14] M. Veverka, "Modry test-nastroj kriminologicke prognozy," Sociologicky Casopis, vol. 7, pp. 76-93, 1971.

[15] M. Dufek, Nektere Poznatky Ke Kriminalni Recidive, VUK pri GP CSSR, Praha, Czech Republic, 1981.

[16] J. Neumann and J. Vonkova, Projekt II. Etapy Vyzkumu Faktoru Ovlivnujicich Resocializaci Propustenych Z VTOS V Postpenitenciarni Fazi. Verifikace Predikcniho Instrumentu, VUK, Praha, Czech Republic, 1987.

[17] R. Heretik and I. Horakova, "Individualna prognostika recidivy u pachatelov homicidia," Trestni Pravo, vol. 5, 2001.

[18] G. Dobrotka, "Prognosticka kriteria recidivy", Socialisticka Zakonnost, vol. 9, pp. 538-540, 1972.
[19] S. Blatnikova and K. Netik, Predikce Vyvoje Pachatele, IKSP, Praha, Czech Republic, 2008.

[20] J. McGuire, What Works in Reducing Criminality. Reducing Criminality-Partnerships and Best Practices, Australian Institute of Criminology, 2000.

[21] P. Raynor, J. Kynch, R. Colin, and S. Merrington, "Risk and need assessment in probation services: an evaluation," Home Office Research Study 211, 2000.

[22] D. P. Farrington, "Implications of criminal career research for the prevention of offending," Journal of Adolescence, vol. 13, no. 2, pp. 93-113, 1990.

[23] M. W. Lipsey, "What do we learn from 400 research studies on the effectiveness of treatment with juvenile delinquents?" in What Works: Reducing Reoffending: Guidelines From Research and Practice, J. McGuire, Ed., pp. 63-78, John Wiley \& Sons, Chichester, UK, 1995.

[24] P. Gendreau and C. Goggin, "Principles of effective correctional programming," Forum on Corrections Research, vol. 8, pp. 38-41, 1996.

[25] F. Lösel, "Evaluating the effectiveness of correctional programs: bridging the gap between research and practice," in Offender Rehabilitation in Practice: Implementing and Evaluating Effective Programs, G. A. Bernfeld, D. P. Farrington, and A. W. Leschied, Eds., pp. 67-92, John Wiley \& Sons, Chichester, UK, 2001.

[26] J. McGuire, "A review of effective interventions for reducing aggression and violence," Philosophical Transactions of the Royal Society B: Biological Sciences, vol. 363, no. 1503, pp. 2577-2597, 2008.

[27] D. A. Andrews and J. Bonta, The Psychology of Criminal Conduct, LexisNexis/Anderson Publishing, Cincinnati, Ohio, USA, 4th edition, 2006.

[28] S. Morton, "Can OASys deliver consistent assessments of offenders? Results from the inter-rater reliability study," 2012, http://webarchive.nationalarchives.gov.uk/20110201125714/http: //www.justice.gov.uk/publications/docs/oasys-research-summary-01-09.pdf.

[29] Risk Assessment Tools Evaluation Directory, Risk Management Authority Scotland, 2007.

[30] M. Petras, E. Biedermannova, and J. Hurka, "Risk/need assessment-novy metodologicky nastroj?” Ceske Vezenstvi, vol. 5, pp. 11-13, 2006.

[31] M. Petras and J. Hurka, "Hodnoceni odsouzenych," Ceske Vezenstvi, vol. 6, pp. 13-14, 2006.

[32] P. Howard, "Improving the prediction of re-offending using the Offender Assessment System," 2012, http://webarchive.nationalarchives.gov.uk/20110201125714/http://www.justice.gov.uk/publications/docs/oasys-research-summary-02-09.pdf.

[33] P. Howard, B. Francis, K. Soothill, and L. Humpreys, OGRS 3: The Revised Offender Group Reconviction Scale, Ministry of Justice, London, UK, 2009, http://eprints.lancs.ac.uk/49988/1/ ogrs3.pdf.

[34] M. Yang, S. C. P. Wong, and J. Coid, "The efficacy of violence prediction: a meta-analytic comparison of nine risk assessment tools," Psychological Bulletin, vol. 136, no. 5, pp. 740-767, 2010. 

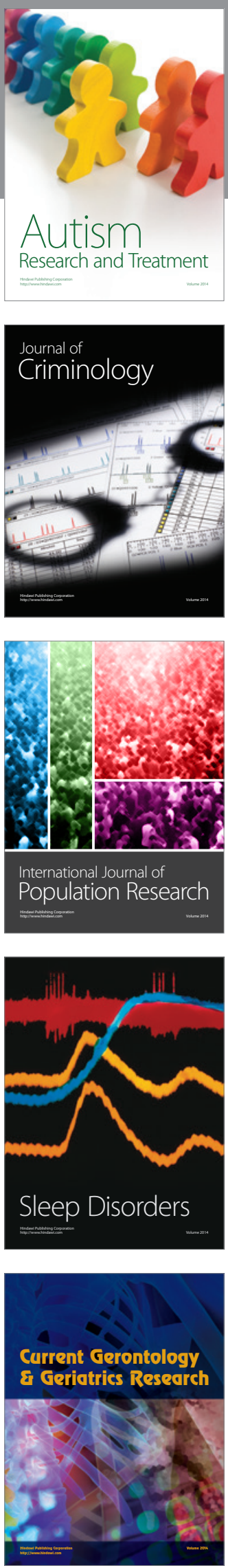
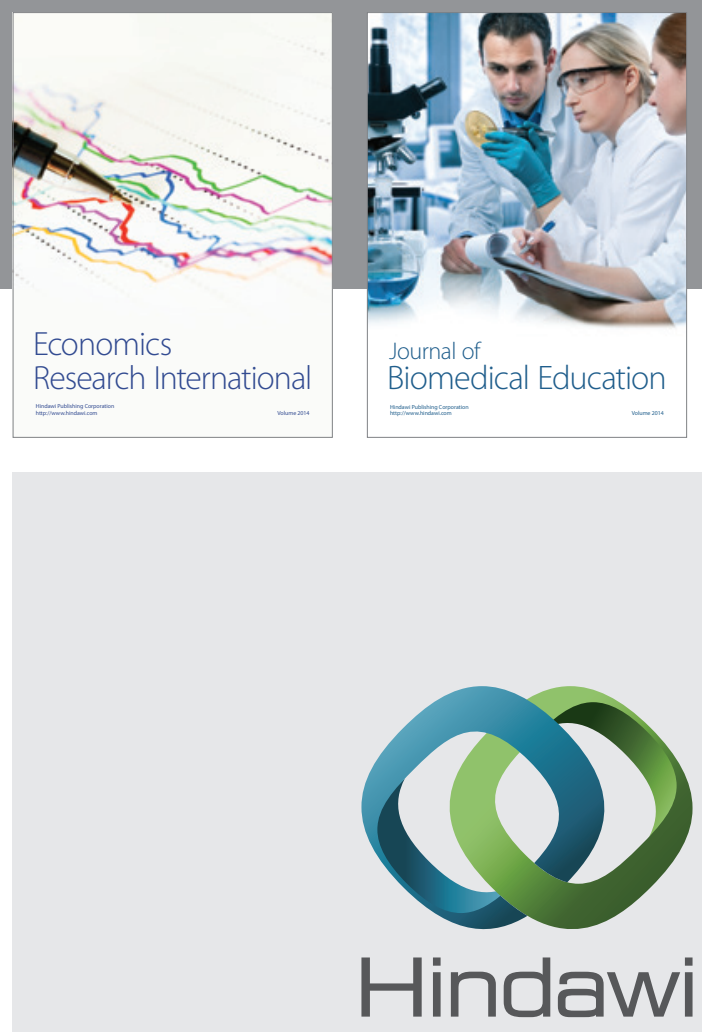

Submit your manuscripts at

http://www.hindawi.com
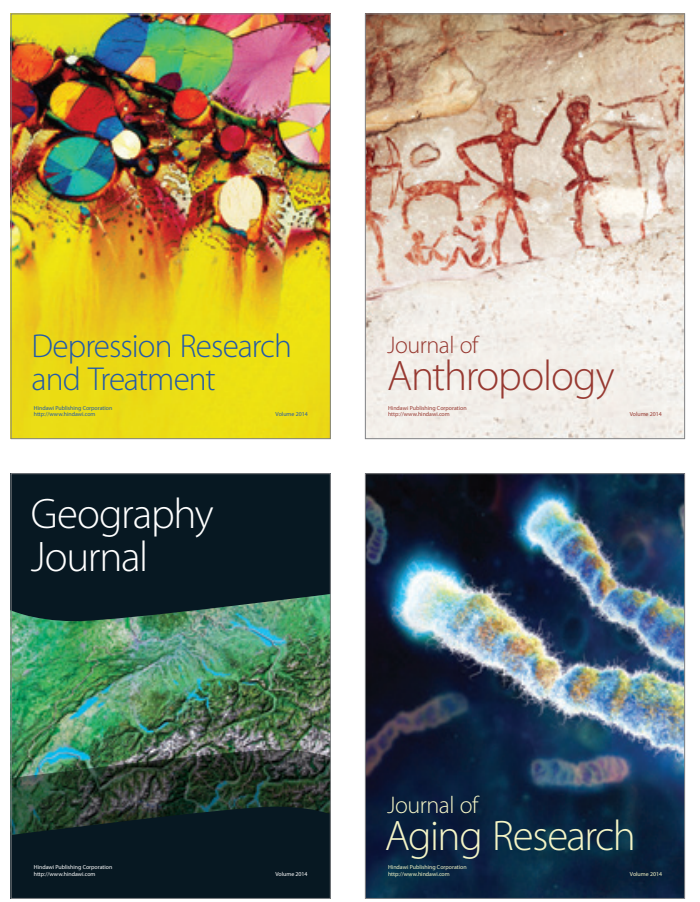
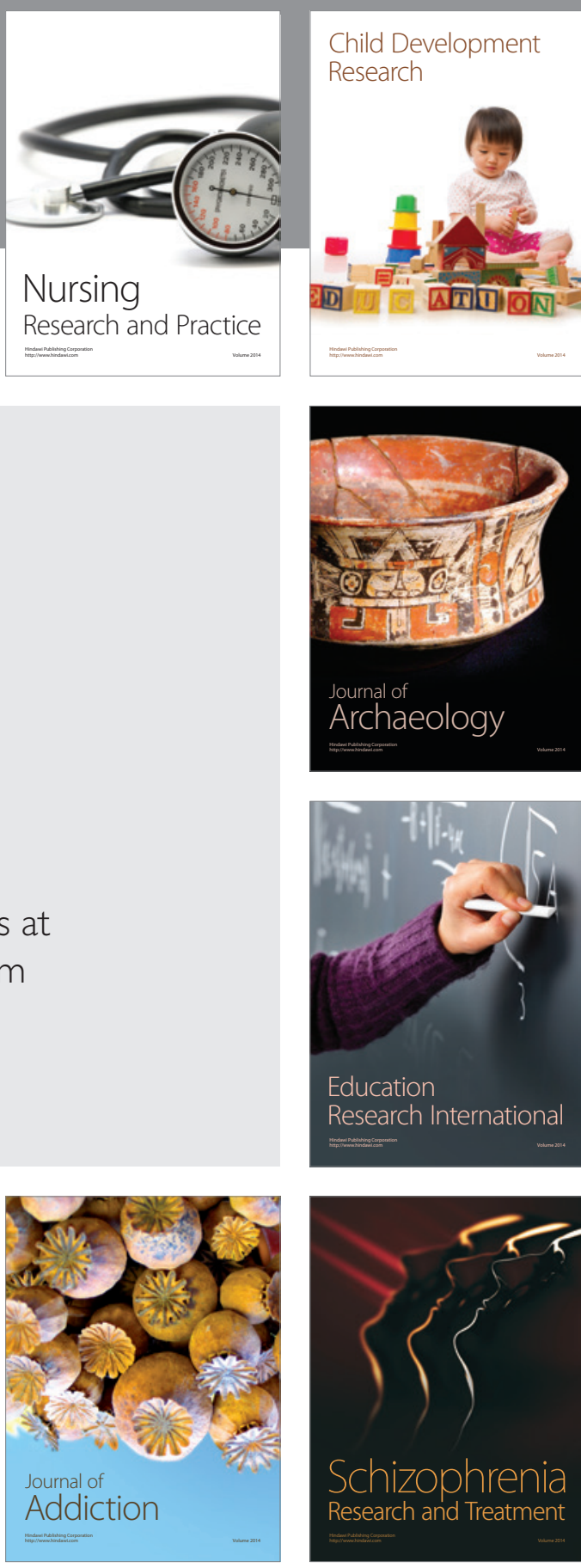

(D)
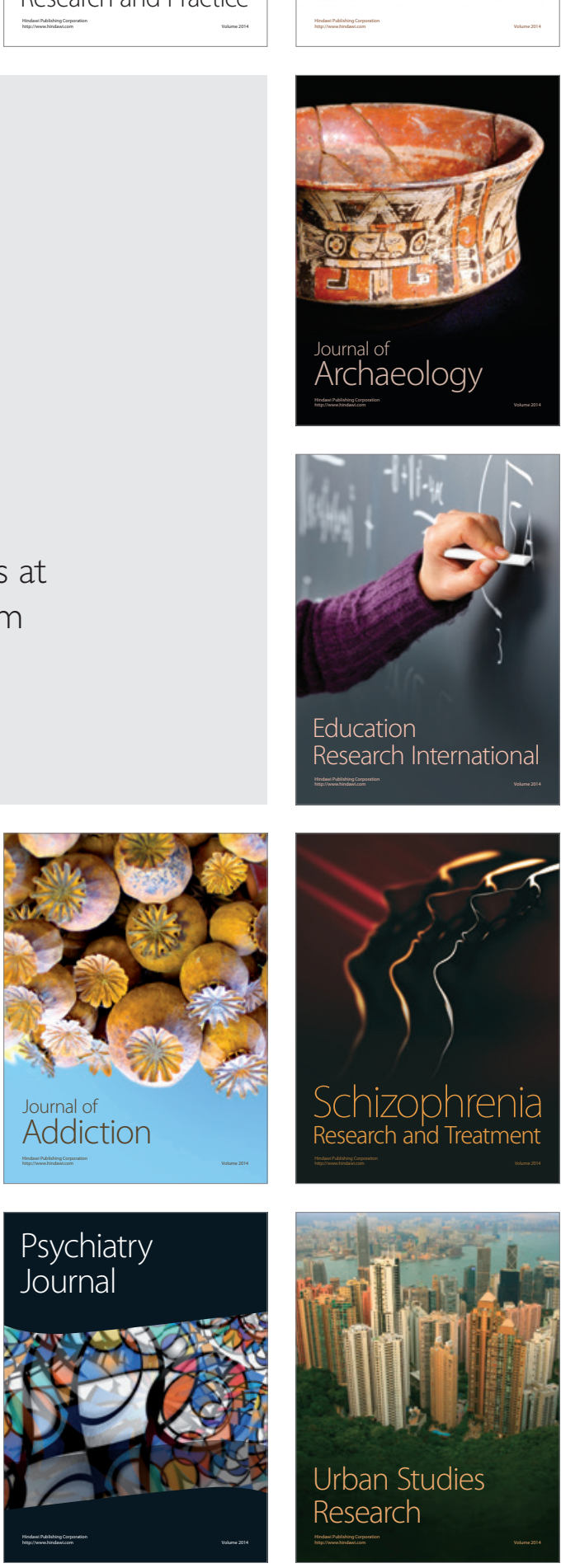